03.2

\title{
Влияние концентрации капель воды в аэрозольном облаке на скорости их испарения
}

\author{
(C) Р.С. Волков, С.А. Керимбекова, П.А. Стрижак \\ Национальный исследовательский Томский политехнический университет, Томск, Россия \\ E-mail: romanvolkov@tpu.ru
}

Поступило в Редакцию 29 марта 2021 г.

В окончательной редакции 27 июля 2021 г.

Принято к публикации 4 августа 2021 г.

\begin{abstract}
Представлены результаты экспериментальных исследований интегральных характеристик испарения капель воды в составе аэрозольного облака (варьируемые параметры: начальный радиус капель $0.1-0.25 \mathrm{~mm}$, концентрация капель воды $0.03-0.11 / \mathrm{m}^{3}$, температура продуктов сгорания $\left.573-873 \mathrm{~K}\right)$. Установлены диапазоны изменения массовой скорости испарения воды в зависимости от концентрации капель в аэрозольном облаке и их начальных размеров. Получены аппроксимационные выражения для установленных зависимостей. Предложен подход к определению скорости испарения капель аэрозоля с учетом известных значений скорости испарения одиночной капли.
\end{abstract}

Ключевые слова: капля воды, аэрозоль, испарение, концентрация капель.

DOI: 10.21883/PJTF.2021.22.51723.18791

Результаты исследований процессов испарения капель в газовой среде с различной концентрацией жидкой и газовой фаз имеют большое практическое значение, так как испарение капель различных жидкостей является основным процессом многих газопарокапельных технологий [1]. Актуальна задача выбора исходных параметров аэрозоля для управления характеристиками испарения [2]. Особенно важно оптимизировать эти процессы при высоких температурах газовой среды (> $500 \mathrm{~K})$ [3], так как это позволит существенно сэкономить энергетические и временны́е ресурсы. В настоящее время, несмотря на известность определенной совокупности публикаций в области изучения испарения аэрозольных потоков, в частности [4], недостаточно информации о значениях массовых скоростей испарения малых по размерам капель $(<0.5 \mathrm{~mm})$. Это связано как со значительными трудностями проведения экспериментов, так и с высокими требованиями к погрешностям измерения ключевых параметров, обусловленными взаимным влиянием соседних капель [5]. При разработке математических моделей часто используется допущение о том, что вся подведенная к поверхности капель тепловая энергия расходуется на реализацию фазовых превращений [6]. В [7] показано, что важную роль играют процессы прогрева капель, а также парогазовых слоев вокруг них, в особенности при рассмотрении аэрозольных потоков. При этом на характеристики испарения значительное влияние оказывают как дисперсность аэрозоля, так и объемная концентрация капель в потоке. Поэтому рациональным представляется экспериментальное определение зависимостей скоростей испарения жидкости в высокотемпературной среде от концентрации капель и их размеров. В этом состоит цель настоящей работы.
При проведении экспериментов использован стенд (рис. 1,a), схема которого аналогична описанной в $[7,8]$. Стенд оснащен передвижной системой регистрации для измерения концентрации и размеров капель на разных участках движения аэрозоля в вертикальном канале с высокотемпературными газами. Для генерации аэрозольного потока применялась система, состоящая из емкости 1 с водой (под давлением $P=200-300 \mathrm{kPa}$ ), канала подачи жидкости 2 и форсунки 3. Использовалась распылительная форсунка, генерирующая полидисперсный поток капель радиусами $R_{d}=0.1-0.25 \mathrm{~mm}$ (рис. $\left.1, b\right)$. Аэрозольный поток 4 исследуемой дисперсности попадал в цилиндрический канал 5 (высота $1 \mathrm{~m}$, внутренний диаметр $0.2 \mathrm{~m}$ ) с продуктами сгорания. В основании канала 5 , состоящего из жаростойкого (до $2000 \mathrm{~K}$ ) светопрозрачного материала, устанавливалась подложка 7 (высота $0.1 \mathrm{~m}$, внутренний диаметр $0.15 \mathrm{~m}$, внешний диаметр $0.19 \mathrm{~m})$, заполненная по периметру керосином марки ТС-1 [8]. Перед проведением каждого опыта топливо в подложке 7 поджигалось, цилиндр заполнялся восходящим потоком продуктов сгорания. Скорость движения потока газов регулировалась за счет изменения давления с использованием вытяжной системы 14 и составляла в экспериментах $U_{g} \approx 1.5 \mathrm{~m} / \mathrm{s}$. Контроль температуры продуктов сгорания $\left(T_{g}=573-873 \mathrm{~K}\right)$ осуществлялся по методике [3] хромель-алюмелевыми термопарами 6 (диапазон $223-1473 \mathrm{~K}$, погрешность $2.5 \mathrm{~K}$ ), установленными на трех высотах $(0.25,0.5,0.75 \mathrm{~m})$ относительно основания цилиндрического канала. Установлено, что температура продуктов сгорания снижалась от 873 до $573 \mathrm{~K}$ по мере движения от основания канала до его верхней части.

Для регистрации размеров капель аэрозоля применялся оптический метод „Shadow Photography“ (SP) [7,8]. 

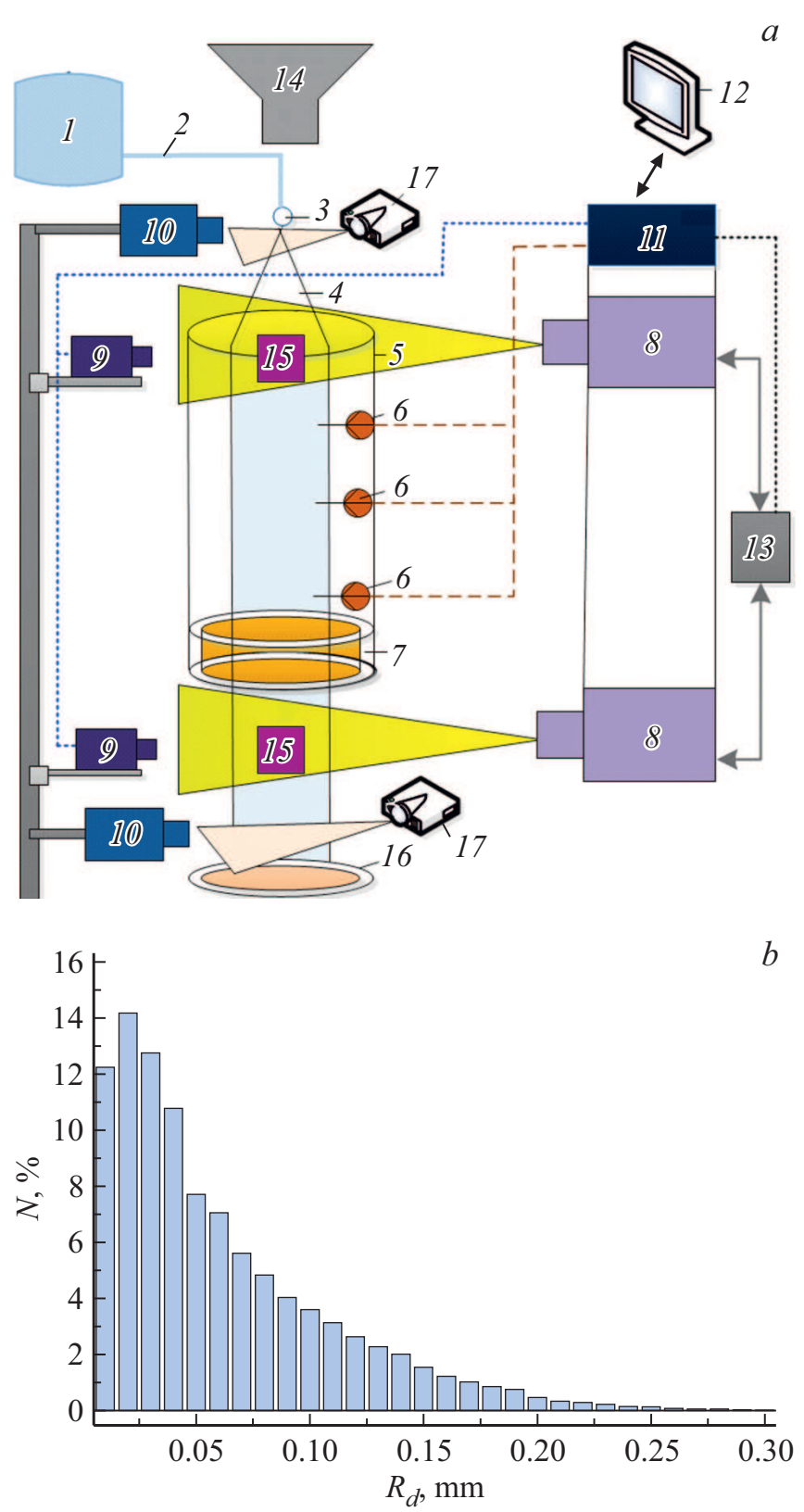

Рис. 1. $a-$ схема экспериментального стенда. 1 - емкость с водой, 2 - канал подачи воды, 3 - распылительная форсунка, 4 - капельный поток, 5 - жаропрочный цилиндр, 6 - термопары, 7 - горелка, 8 - двойной импульсный Nd:YAG-лазер, 9 - кросскорреляционная камера, 10 - скоростная видеокамера, 11 - синхронизатор для персонального компьютера, кросскорреляционных камер и лазера, 12 - персональный компьютер, 13 - генератор лазерного излучения, $14-$ вытяжная система, 15 - рассеивающий диффузный экран со световодом, 16 - каплеуловитель, $17-$ световой прожектор. $b$ - распределение количества капель $N$ по размерам для используемой в экспериментах форсунки.

Для реализации метода SP использовался кросскорреляционный программно-аппаратный комплекс на базе двойного твердотельного Nd:YAG-лазера 8 „Quantel EverGreen 70“ (длина волны $532 \mathrm{~nm}$, частота повторе- ния $15 \mathrm{~Hz}$, максимальная энергия в импульсе $72 \mathrm{~mJ})$ и CCD-видеокамеры 9 „ImperX IGV-B2020M““ (разрешение кадра $2048 \times 2048$ ріх, частота съемки до $25 \mathrm{fps,}$ разрядность $8 \mathrm{bit}$ ) с установленным макрообъективом „Nikon Micro-Nikkor 200mm f/4D ED-IF A“. Nd:YAGлазер 8 посредством оптического световода подключался к рассеивающему диффузному экрану 15 . Создавалась фоновая подсветка измерительной области. Выполнялась процедура видеофиксации изображений капель с использованием CCD-видеокамеры 9. Полученные данные обрабатывались с использованием программного обеспечения „Actual Flow“. На первом этапе осуществлялось выделение границ капель программным фильтром „Laplace Edge Detection“. Далее выполнялась нейтрализация шумов на изображениях с использованием „Median Filter“. На последнем шаге задавался порог бинаризации изображений и с использованием процедуры „Bubbles Identification“ определялись радиусы капель $\left(R_{d}\right)$. Погрешности определения $R_{d}$ не превышали $1.5 \%$. Для каждой капли вычислялось абсолютное уменьшение ее среднего радиуса после прохождения канала с высокотемпературными продуктами сгорания $(\Delta R)$.

Параллельно с описанными выше экспериментами выполнялись исследования по определению времени прохождения каплями канала с продуктами сгорания. Применялась система (рис. 1, $a$ ), состоящая из высокоскоростной CMOS-видеокамеры 10 „Phantom MIRO M310“ (разрешение изображения $1280 \times 800$ pix, скорость съемки до $6.5 \cdot 10^{5} \mathrm{fps}$ ) и светодиодного прожектора 17 „Multiled PT-V9 GS Vitec“ (количество светодиодов 24, световой поток $7700 \mathrm{~lm}$, мощность $84 \mathrm{~W}$, угол рассеяния $30^{\circ}$ ). Видеокамерой 10 регистрировались капли на входе и выходе из кварцевого канала 5 . По результатам анализа видеозаписей определялись момент вхождения капель в канал с продуктами сгорания $\left(t_{1}\right)$, а также момент их появления на выходе канала $\left(t_{2}\right)$. Вычислялось время прохождения каплями канала $\Delta t_{d}=t_{2}-t_{1}$. Погрешность определения $\Delta t_{d}$ не превышала $0.03 \mathrm{~s}$.

При идентичных начальных условиях выполнялось не менее десяти экспериментов. По результатам каждого эксперимента вычислялось значение массовой скорости испарения [9]:

$$
W_{e}=\rho_{d}\left(R_{d}-R_{d}^{\prime}\right) / \Delta t_{d}=\rho_{d} \Delta R / \Delta t_{d},
$$

где $\rho_{d}$ - плотность воды $\left[\mathrm{kg} / \mathrm{m}^{3}\right] ; R_{d}, R_{d}^{\prime}-$ начальное и конечное значения радиуса $[\mathrm{m}]$ (определялись по аналогии с $[8]) ; \Delta t_{d}$ - время прохождения каплями канала с продуктами сгорания [s]. Погрешность определения массовой скорости испарения капель не превышала $2.5 \%$.

На рис. 2 представлены установленные зависимости скоростей испарения воды от концентрации и начального размера капель. Из рис. 2, $a$ видно, что для трех исследуемых концентраций капель $\left(0.03,0.05\right.$ и $\left.0.11 / \mathrm{m}^{3}\right)$ динамика изменения скорости испарения сопоставима. 

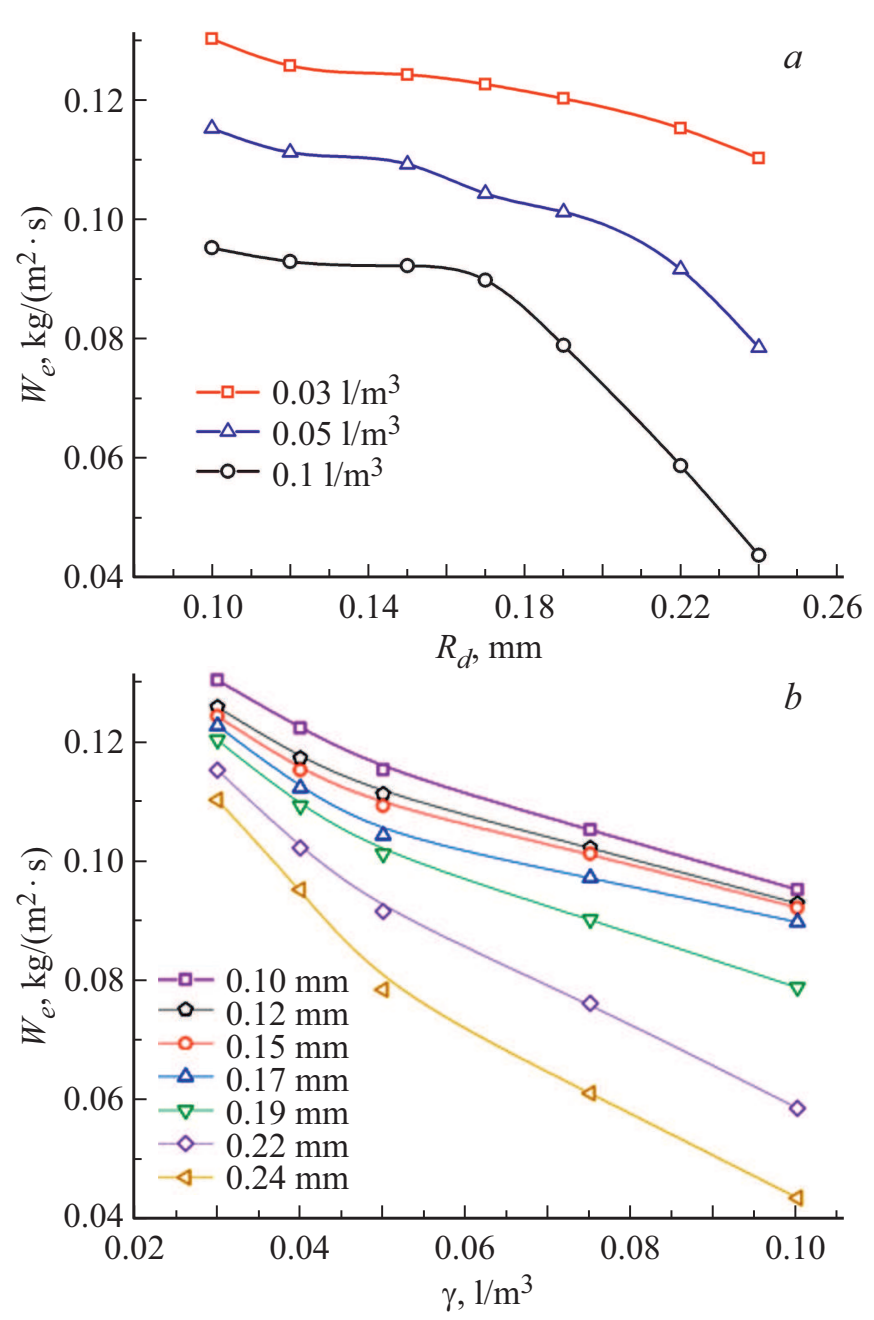

Рис. 2. Значения скоростей испарения капель воды в высокотемпературной газовой среде $\left(T_{g}=573-873 \mathrm{~K}\right)$ с учетом их разных начальных размеров $R_{d}(a)$ и относительной концентрации $\gamma(b)$.

Для капель в потоке с концентрацией $\sim 0.031 / \mathrm{m}^{3}$ значения массовой скорости испарения $W_{e}$ снижались на $15 \%$ с ростом размера капель в диапазоне $0.1-0.24 \mathrm{~mm}$. При концентрации $\sim 0.051 / \mathrm{m}^{3}$ снижение $W_{e}$ составило $32 \%$, при $0.1 \mathrm{l} / \mathrm{m}^{3}-56 \%$. Таким образом, показано, что с ростом начальной концентрации капель в потоке происходит более интенсивное уменьшение $W_{e}$. Однако из рис. 2, $a$ также видно, что чем выше концентрация капель аэрозоля, тем ниже значения скорости испарения при равных начальных радиусах капель. Это обусловлено, во-первых, ростом концентрации паров в аэрозольном потоке и долей жидкой фазы (вода вследствие высокой теплоемкости существенно снижает температуру газов вокруг) в газопарокапельной смеси и, во-вторых, снижением межкапельного расстояния в облаке, что приводит к более сильному влиянию на характеристики испарения соседних капель. По результатам экспериментов (рис. 2) получена группа зависимостей для прогнозирования скорости $\left(\right.$ в $\left.\mathrm{kg} /\left(\mathrm{m}^{2} \cdot \mathrm{s}\right)\right)$ испарения капель в составе аэрозольного облака с концентрацией $0.03-0.11 / \mathrm{m}^{3}$ при известном начальном размере капель

$$
W_{e}=a+b R_{d}+c R_{d}^{2}
$$

и известной их концентрации в потоке

$$
W_{e}=\exp \left(a+b \gamma+c \gamma^{2}\right) .
$$

Коэффициенты аппроксимационных функций (1) и (2) приведены в табл. 1 и 2 (при варьировании параметров потока в диапазоне $R_{d}=0.1-0.24 \mathrm{~mm}$, $\left.\gamma=0.03-0.11 / \mathrm{m}^{3}\right)$. Дополнительно в таблицах приведены значения коэффициентов детерминации $\left(R^{2}\right)$ для полученных аппроксимационных выражений.

Эксперименты показали (рис. 2, $b$ ), что для капель с размерами 0.1-0.17 mm увеличение их концентрации в потоке от 0.03 до $0.1 \mathrm{l} / \mathrm{m}^{3}$ приводит к уменьшению значений скорости испарения на 24-28\%. Для капель с радиусами $R_{d}>0.17 \mathrm{~mm}$ уменьшение скорости испарения более значительно и составило $33-62 \%$. Скорее всего, такой результат обусловлен усиливающимся влиянием свойств воды. В частности, определяющую роль играют высокая теплоемкость жидкости и теплота парообразования. Чем больше размеры капли, тем выше значение энергии, которую необходимо подвести к ее поверхности для интенсификации прогрева и фазовых превращений. Чем выше температура газовой среды, тем интенсивнее реализуются прогрев и испарение капли. При этом в потоке дымовых газов с изменяющейся температурой важную роль играют фактор протяженности канала и градиенты температуры. От этого существенно зависит подводимый к поверхности капли тепловой поток. Также важную роль играет фактор полидисперсности потока капель. Крупные капли при испарении создают буферную паровую зону для мелких капель, что снижает скорости прогрева и испарения последних. Это приводит к изменению скоростей движения капель и интенсификации их взаимодействия в режимах коагуляции, дробления, отскока и разлета.

На практике определение скоростей испарения мелких капель (особенно в аэрозольном потоке) является сложной задачей, требующей специализированного высокоточного оборудования. Поэтому по результатам исследований (рис. 2) предложен подход к определению скорости испарения капель аэрозоля $\left(R_{d}=0.1-0.25 \mathrm{~mm}\right)$, предполагающий ее прогнозирование с учетом известных/вычисленных значений скорости испарения одиночной капли. Использовались значения скорости испарения одиночной капли, полученные в условиях конвективного обтекания горячим потоком воздуха [9]. Так, при температурах $\sim 773 \mathrm{~K}$ (соответствует средним значениям в экспериментах с водяным аэрозолем) значение массовой скорости испарения для одиночной капли при $R_{d}^{*} \approx 1.33 \mathrm{~mm}$ составило $W_{e}^{*} \approx 0.032 \mathrm{~kg} /\left(\mathrm{m}^{2} \cdot \mathrm{s}\right)$, при $R_{d}^{*} \approx 1.53 \mathrm{~mm}-W_{e}^{*} \approx 0.029 \mathrm{~kg} /\left(\mathrm{m}^{2} \cdot \mathrm{s}\right), \quad$ при $R_{d}^{*} \approx 1.68 \mathrm{~mm}-W_{e}^{*} \approx 0.025 \mathrm{~kg} /\left(\mathrm{m}^{2} \cdot \mathrm{s}\right)$. Аппроксимация 
Таблица 1. Коэффициенты функции $W_{e}=f\left(R_{d}\right)\left(\right.$ при $\left.R_{d}=0.1-0.24 \mathrm{~mm}\right)$

\begin{tabular}{c|c|c|c|c}
\hline \multirow{2}{*}{ Концентрация капель, $1 / \mathrm{m}^{3}$} & \multicolumn{2}{|c|}{ Коэффициенты параболической функции } & \multirow{2}{*}{$R^{2}$} \\
\cline { 2 - 5 } & $a$ & $b$ & $c$ & 0.93794 \\
0.03 & 0.13002 & 0.03482 & -0.048044 & 0.98210 \\
0.1 & 0.09611 & 0.34487 & -1.71357 & 0.99251
\end{tabular}

Таблица 2. Коэффициенты функции $W_{e}=f(\gamma)\left(\right.$ при $\left.\gamma=0.03-0.11 / \mathrm{m}^{3}\right)$

\begin{tabular}{c|c|c|c|c}
\hline \multirow{2}{*}{ Начальный радиус капель, $\mathrm{mm}$} & \multicolumn{2}{|c|}{ Коэффициенты экспоненциальной функции } & \multirow{2}{*}{$R^{2}$} \\
\cline { 2 - 4 } & $a$ & $b$ & 22.23561 & 0.98616 \\
0.1 & -1.84714 & -7.2452 & 24.84468 & 0.99137 \\
0.12 & -1.88323 & -7.37762 & 28.96855 & 0.98578 \\
0.17 & -1.88796 & -7.80628 & 51.62496 & 0.97842 \\
0.19 & -1.82845 & -10.91542 & 36.10507 & 0.99007 \\
0.22 & -1.84682 & -10.47471 & 17.54703 & 0.99266 \\
0.24 & -1.84025 & -11.5712 & 44.71094 & 0.99092
\end{tabular}

результатов настоящей работы и результатов [8] показала, что при $\gamma=0$ и $R_{d}=0.1-0.25 \mathrm{~mm}$ (для $T_{g}=750 \mathrm{~K}$ ) значения $W_{e}$ совпадают и изменяются в среднем в диапазоне $0.15-0.17 \mathrm{~kg} /\left(\mathrm{m}^{2} \cdot \mathrm{s}\right)$. На основании данного заключения получена формула для оценки скорости испарения капель аэрозоля

$$
W_{e}=k\left(R_{d}^{*} / R_{d}\right)^{2} W_{e}^{*}
$$

на основе коэффициента

$k=[-0.005+1.666 \exp (-24.058 \gamma)]\left(R_{d}^{*} / R_{d}\right)^{(-1.658+7.584 \gamma)}$,

где $R_{d}, R_{d}^{*}$ - радиусы капли аэрозоля и одиночной капли $[\mathrm{mm}] ; W_{e}, W_{e}^{*}$ - массовые скорости испарения капли аэрозоля и одиночной капли $\left[\mathrm{kg} /\left(\mathrm{m}^{2} \cdot \mathrm{s}\right)\right]$. На рис. 3 приведена номограмма, иллюстрирующая значения коэффициента $k$ при отношении $R_{d}^{*} / R_{d}=4-18$ и концентрации капель аэрозоля $\gamma=0-0.11 / \mathrm{m}^{3}$. Как итог, экспериментально определив скорость испарения $\left(W_{e}^{*}\right)$ крупной одиночной капли $\left(R_{d}^{*}>1 \mathrm{~mm}\right)$ с использованием формул (3) и (4), задаваясь значениями среднего радиуса капель $R_{d}$ и их концентрации $\gamma$, можно вычислить скорость испарения капель аэрозоля в потоке. Численные оценки показали, что погрешность определения $W_{e}$ с использованием такого подхода составила 7-10\%. В дальнейшем целесообразными представляются расширение предложенного подхода к определению $W_{e}$ на больший диапазон температур и оценка его правомерности при определении скоростей испарения капель различных многокомпонентных жидкостей.

Таким образом, проведенные эксперименты показали, что скорости прогрева и испарения капель воды как элементов аэрозоля в высокотемпературной газовой

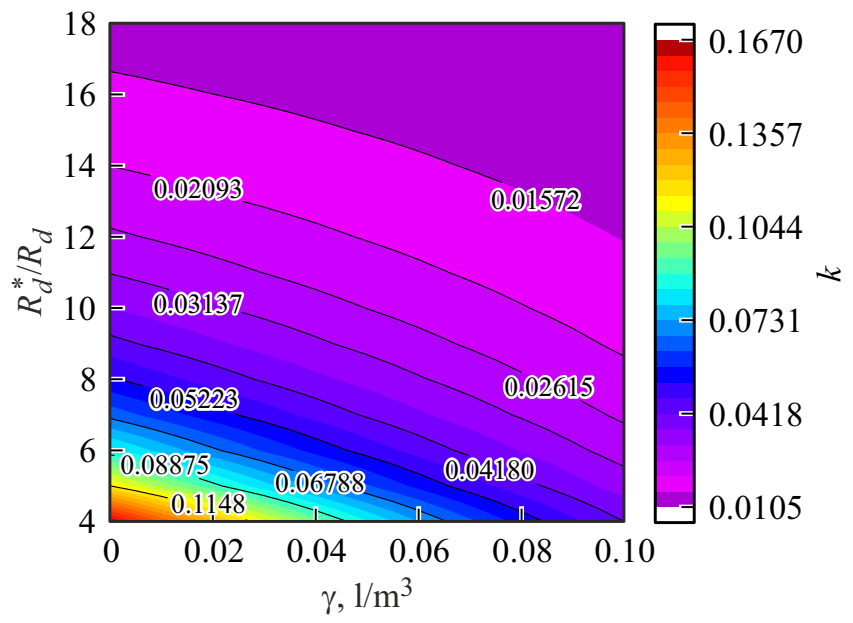

Рис. 3. Номограмма, иллюстрирующая значения коэффициента $k$ при разном отношении $R_{d}^{*} / R_{d}$ и относительной концентрации капель аэрозоля $\gamma$.

среде главным образом зависят от их концентрации и начальных размеров. Полученные по результатам обработки опытов математические выражения $W_{e}=f\left(R_{d}\right)$, $W_{e}=f(\gamma)$ и $W_{e}=f\left(W_{e}^{*}\right)$ позволяют выполнять прогнозирование интенсивности испарения аэрозольных облаков по результатам опытов с одиночными каплями.

\section{Финансирование работы}

Работа выполнена при поддержке Российского фонда фундаментальных исследований (грант 18-38-00007). 


\section{Конфликт интересов}

Авторы заявляют, что у них нет конфликта интересов.

\section{Список литературы}

[1] Е.М. Бочкарева, М.К. Лей, В.В. Терехов, В.И. Терехов, ИФЖ, 92 (5), 2208 (2019). DOI: 10.1007/s10891-019-02031-4

[2] П.В. Акулич, ИФЖ, 92 (2), 404 (2019). DOI: $10.1007 / \mathrm{s} 10891-019-01943-5$

[3] В.А. Архипов, С.А. Басалаев, Н.Н. Золоторёв, К.Г. Перфильева, А.С. Усанина, Письма в ЖТФ, 46 (8), 25 (2020). DOI: 10.21883/PJTF.2020.08.49304.18209

[4] В.А. Архипов, С.А. Басалаев, А.И. Коноваленко, К.Г. Перфильева, Письма в ЖТФ, 46 (12), 40 (2020). DOI: 10.21883/PJTF.2020.12.49527.18300

[5] G. Castanet, L. Perrin, O. Caballina, F. Lemoine, Int. J. Heat Mass Transfer., 93, 788 (2016).

DOI: 10.1016/j.ijheatmasstransfer.2015.09.064

[6] V. Ramanauskas, G. Miliauskas, Int. J. Heat Mass Transfer., 131, 546 (2019).

DOI: 10.1016/j.ijheatmasstransfer.2018.06.095

[7] И.С. Войтков, Г.В. Кузнецов, П.А. Стрижак, Письма в ЖТФ, 43 (6), 48 (2017). DOI: 10.21883/PJTF.2017.06.44403.16525

[8] G.V. Kuznetsov, P.A. Strizhak, R.S. Volkov, O.V. Vysokomornaya, Int. J. Therm. Sci., 108, 218 (2016). DOI: 10.1016/j.ijthermalsci.2016.05.019

[9] R.S. Volkov, P.A. Strizhak, Appl. Therm. Eng., 127, 141 (2017). DOI: 10.1016/j.applthermaleng.2017.08.040 